Document downloaded from:

http://hdl.handle.net/10251/77487

This paper must be cited as:

Bartovsky ., P.; Ribes, A.; Agostini, A.; Benito Beorlegui, A.; Martínez-Máñez, R. (2014). Delivery modulation in silica mesoporous supports via functionalization in the pore outlets with a Zn(II) bis(2-pyridylmethyl)amine complex. Inorganica Chimica Acta. 417:263-269. doi:10.1016/j.ica.2014.01.036.

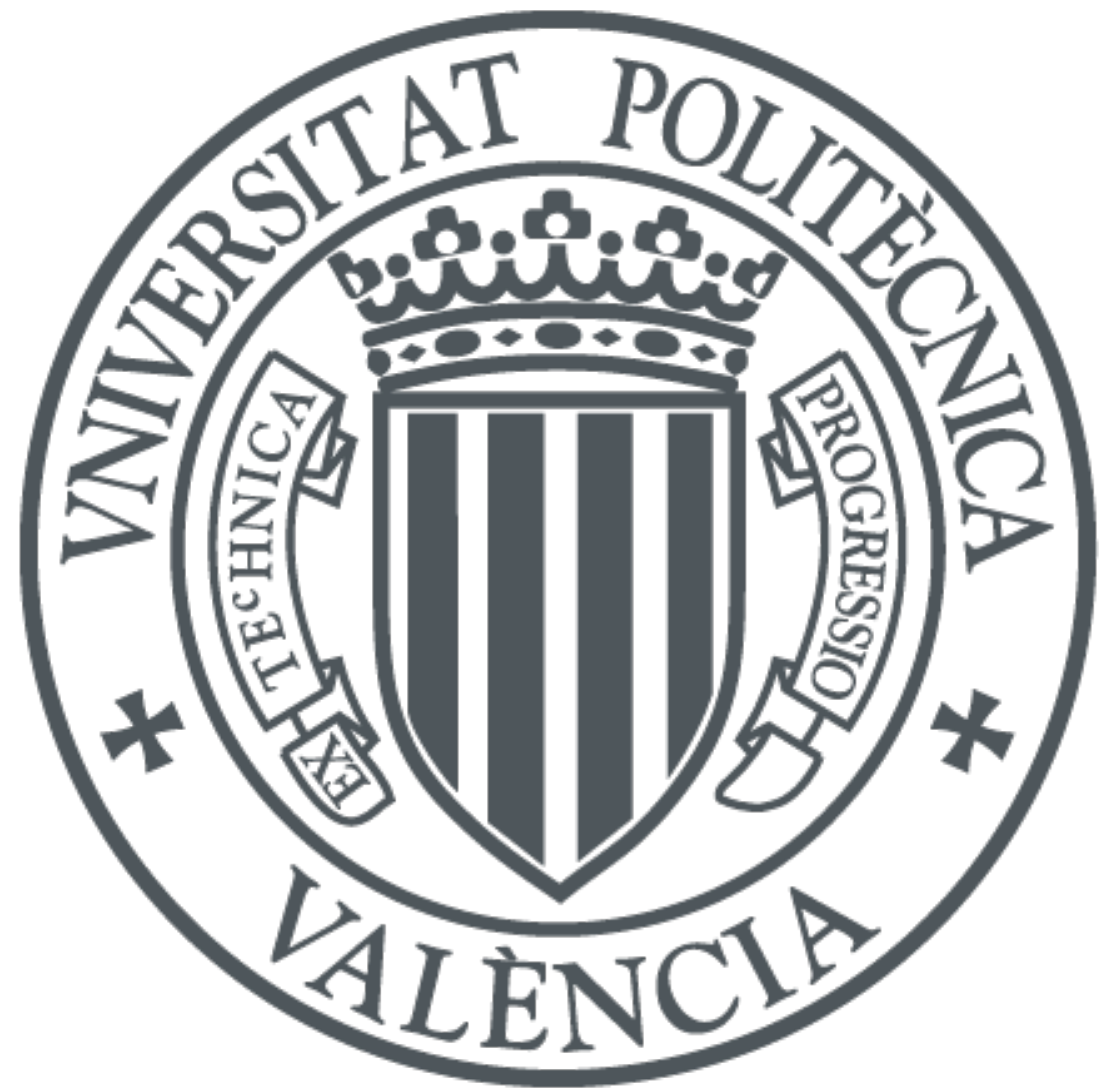

The final publication is available at

http://dx.doi.org/10.1016/j.ica.2014.01.036

Copyright Elsevier

Additional Information 


\title{
Delivery modulation in silica mesoporous supports via functionalization in the pore outlets with a $\mathrm{Zn(II)-}$ bis(2-pyridylmethyl)amine complex.
}

\author{
Pavel Bartovsky, ${ }^{\mathrm{a}, \mathrm{b}}$ Angela Ribes, ${ }^{\mathrm{a}, \mathrm{b}}$ Alessandro Agostini, ${ }^{\mathrm{a}, \mathrm{b}}$ Angel Benito ${ }^{\mathrm{a}, \mathrm{b}}$ \\ and Ramón Martínez-Máñez ${ }^{\mathrm{a}, \mathrm{b} *}$ \\ a) Centro de Reconocimiento Molecular y Desarrollo Tecnológico (IDM), Unidad \\ mixta Universidad Politécnica de Valencia-Universidad de Valencia, Spain. \\ Departamento de Química, Universidad Politécnica de Valencia, Camino de Vera \\ s/n, 46022, Valencia. E-mail: rmaez@qim.upv.es. Fax: (+34) 963879349 \\ b) CIBER de Bioingeniería, Biomateriales y Nanomedicina (CIBER-BBN)
}

Keywords: mesoporous silica; Zn(II)-2,2'-dipicolylamine complexes; gated materials; controlled release; anions; nucleotides

Abstract: This paper focuses on the study of the release behaviour of an entrapped dye (i.e. $\left.\left[\mathrm{Ru}(\mathrm{bipy})_{3}\right]^{2+}\right)$ in the presence of different anions from silica mesoporous supports functionalized in the external surface with Zn(II)-bis(2-pyridylmethyl)amine complexes (solid SZn). The Zn(II)-dipicolylamine complexes, anchored in the external surface of SZn, are too small to induce pore blockage and the loaded $\left[\mathrm{Ru}(\mathrm{bipy})_{3}\right]^{2+}$ dye is freely to diffuse from the inner of the pores to the bulk solution. Addition of selected anions $\left(\mathrm{F}^{-}\right.$, $\mathrm{Cl}^{-}, \mathrm{Br}^{-}, \mathrm{I}^{-}, \mathrm{AcO}^{-}, \mathrm{BzO}^{-}, \mathrm{SO}_{4}{ }^{2-}, \mathrm{NO}_{3}{ }^{-}, \mathrm{PO}_{4}{ }^{3-}, \mathrm{P}_{2} \mathrm{O}_{7}{ }^{2-}, \mathrm{ATP}, \mathrm{ADP}$ and AMP) modulates the release of the entrapped cargo. It was observed that the interaction of the $\mathrm{Zn}$ (II) complex with bulky organic phosphates (such as ATP, ADP and AMP), pyrophosphate and phosphate resulted in a remarkable inhibition of the $\left[\mathrm{Ru}(\mathrm{bipy})_{3}\right]^{2+}$ dye. Small or poorly coordinating anions induced moderate or negligible inhibitions of $\left[\mathrm{Ru}(\mathrm{bipy})_{3}\right]^{2+}$ release. The delivery observed was clearly related with the ability of the anion to form complexes with the Zn(II)-dipicolylamine groups and with the size and charge of the anion.

\section{Introduction}

Since some years ago the design of systems able to deliver their cargo in a controlled fashion had been a very active research field. The controlled delivery of certain compounds such as drugs is of crucial interest in many scientific disciplines including biology, pharmacology and medicine. In particular a great amount of new delivery dispositives using several strategies have been developed. For instance, microcapsules,[1] micelles,[2] vesicles,[3] dendrimers[4] or polymeric matrixes[5] have been extensively employed for controlled release of target guests.

Silica mesoporous supports (SMPS) were discovered at the end of the past century and were some years later used as a new platform for the design of new cargo storage and delivery scaffoldings.[6] This interest was mainly related to the unique characteristics of SMPS such as their high surface area, thermal stability, the presence of tunable pore sizes, homogeneous pore distribution and easy modification via diverse functionalization chemistries.[7-11] The first silica mesoporous-based system used in controlled release applications of chemical species was reported by the Vallet-Regí research group.[12] In this seminal study a MCM-41 scaffold was loaded with ibuprofen as a model compound and the drug delivery kinetics was studied. In further 
studies by the same authors and other groups it was observed that the functionalization of the inner surface with selected organic moieties could control the amount of loaded cargo and also control the delivery rate via supramolecular interactions between the guest and the surface-anchored organic moieties.[13] However this approach shows certain limitations related with the premature release of the entrapped cargo and with the proper design of systems able to show of both selective molecule accommodation and appropriate sustained delivery.

Moreover, in a further advance in this field, it was demonstrated that it is possible to incorporating in the external surface of SMPS functional groups capable of being opened or closed at will. This has been recently resulted in the design of gatedSMPS showing "zero delivery" and capable to release their cargo on-command in response to specifically designed external stimuli.[14-16] The first gate-like hybrid material was developed by Fujiwara et al.[17] Their innovative system was able to control cholestane and other molecules transport by irradiation with the appropriate light. Since then, and using a similar approach, different gated-SMPS have been described which can be classified depending on the external stimulus used to trigger cargo delivery. In particular nowadays gated materials responding to light,[18-20] redox reactions,[21-23] $\mathrm{pH},[24-26]$ changes in polarity,[27] temperature[28-30] and certain bio-molecules[31-33] as stimuli have been reported.

Apart of the obvious use of these materials in drug delivery applications gated supports have also been applied to the design of chromo-fluorogenic probes. In this case the mesoporous solids are used as reservoirs for dyes, and equipped with molecular entities (gates) that controlled the release of the entrapped cargo.[34] The central idea relies on the fact that coordination or reaction of the target analyte with the binding sites (which are the gate-keepers of the molecular gates) could modulate the transport of the entrapped indicator from the pores to the solution allowing for instance chromo- and/or fluorogenic assessment. In this context two basic approaches could be considered. In the first case there is an open gate-like system that is able to deliver the entrapped dye to the solution and that is selectively closed in the presence of certain species in the solution. In a second and more advanced protocol, the gate is initially closed and only upon addition of the target analyte is it selectively opened, allowing the release of the entrapped dye resulting in a chromo- and/or fluorogenic event. This approach using gated ensembles detach the recognition step from the signaling event, therefore making signaling independent of the host-guest stoichiometry and enabling signal amplification.[35-37] The latter is due to that fact that the presence of a few target molecules can induce the release of a large number of fluorescent molecules. This strategy harbors enormous potential for the development of novel signaling systems with enhanced features and it is highly flexible given the possible selection of different porous supports, diverse guest-selective binding sites (molecular gates) and a wide range of indicators. Following this gated approach hybrid sensory materials for the recognition of ATP,[38-41] long chain carboxylates,[27] methylmercury,[42] borate,[43] sulfathiazole,[44] oligonucleotides,[45] anionic surfactants,[46] nerve agent simulants,[47] finasteride,[48] nitroaromatic explosives,[49,50] mycoplasma,[51] thrombin,[52] TATP,[53] glucose,[54-57] adenosine[58] and certain cations[59-61] have been described recently.

The above examples, for sensing or drug delivery, show the appearance of synergistic features arising from the combination of solid structures and suitable functional groups. In these systems surface functionalization is a key issue. Moreover, apart of designing systems able to control the opening or close of the pores, it is also possible to include molecular obstacles at the pore outlets able to modulate mass 
transport at nanometric level.[62] Besides, bearing in mind that it is possible to include chemical modification of the inner pore surface with the objective of guest loading in the pore voids, the use of functionalized mesoporous supports is a promising platform for the design of more complex delivery systems in which the events of guest loading (via functionalization of the inner pores), on-command delivery (via anchoring capped or gated ensembles) and modulation of the delivery rate (via incorporation of molecular obstacle at the pore outlets) can be envisioned.

Within this background there are very few work related with the use of metal complexes in mesoporous materials for the design of systems able to control cargo delivery via the interaction of the attached complexes with certain anions. In this particular context we have focused our attention to potentially control the delivery in SMPS via the chemical modification of the pore entrances by covalent bonding of a complex (i.e. Zn(II)-2,2'-dipicolylamine) as model barrier. It was expected that the presence of different anions able to coordinate with the complexes at the external surface could lead to changes in guest delivery from the inner pores to the solution, allowing a tuned release of the cargo. This effect has been studied through the delivery of a model compound (the $\left[\mathrm{Ru}(\text { bipy })_{3}\right]^{2+}$ dye probe). Small anions were unable to block the pores whereas larger anions (ATP, ADP, pyrophosphate and phosphate) induced several degrees of dye release inhibition.

\section{Experimental section}

2.1. General methods: Powder $X$-ray diffraction, TG analysis, and $\mathrm{N}_{2}$ adsorptiondesorption techniques were used to characterize the prepared materials. X-ray measurements were carried out using a Philips D8 Advance diffractometer using CuK $\alpha$ radiation. Thermo-gravimetric analyses were carried out on a TGA/SDTA 851e Mettler Toledo balance, using an oxidant atmosphere (air, $80 \mathrm{~mL} / \mathrm{min}$ ) with a heating program consisting of a heating ramp of $10 \mathrm{~K}$ per minute from $293 \mathrm{~K}$ to $1273 \mathrm{~K}$ and an isothermal heating step at this temperature for 30 minutes. $\mathrm{N}_{2}$ adsorption-desorption isotherms were recorded with a Micromeritics ASAP2010 automated sorption analyzer. Samples were degassed at $393 \mathrm{~K}$ in vacuum overnight. Specific surface areas were calculated from the adsorption data in the low pressures range using the BrunauerEmmett-Teller (BET) model. Pore size was determined following the Barret-JoynerHalenda (BJH) method. TEM images were obtained with a $100 \mathrm{kV}$ Philips CM10 microscope. UV-visible spectroscopy was carried out on a Lambda $35 \mathrm{UV} / \mathrm{Vis}$ Spectrometer (Perkin Elmer Instruments) at $298 \mathrm{~K}$. Fluorescence spectroscopy studies were carried out at $298 \mathrm{~K}$ with a Jasco Spectrofluorometer FP-8500 and with a Felix 32 Analysis, version 1.2 (Build 56) PTI (Photon Technology International). 1D NMR spectra were obtained on a Bruker AVANCE III $400 \mathrm{MHz}$ Spectrometer, where ${ }^{1} \mathrm{H}$ NMR spectra were recorded at $400 \mathrm{MHz}$ at $298 \mathrm{~K}$, while ${ }^{13} \mathrm{C} \mathrm{NMR}$ spectra were recorded at $100 \mathrm{MHz}$ at $298 \mathrm{~K}$. The NMR samples were dissolved in deuterated solvents purchased from Cambridge Isotope Labs or Sigma-Aldrich, and TMS or the residual solvent were used as internal standard. Electron impact ionization mass spectrometry (MS-EI) was performed on a Thermo Finnigan MAT SSQ710 single stage quadropole instrument. Matrix-assisted laser-desorption/ionization mass spectrometry was performed on a Bruker Autoflex III Smartbeam mass spectrometer, utilizing a 2,5dihydroxybenzoic acid (DHB) matrix.

2.2. Chemicals: The chemicals tetraethylorthosilicate (TEOS) (98\%), $n$-cetyltrimethylammonium bromide $(\mathrm{CTAB})(\geq 99 \%)$, sodium hydroxide $(\geq 98 \%)$, triethanolamine $\left(\mathrm{TEAH}_{3}\right)(\geq 99 \%)$, tris(2,2'-bipyridyl)dichlororuthenium(II) hexahydrate 
([Ru(bipy) $\left.)_{3}\right] \mathrm{Cl}_{2} \cdot 6 \mathrm{H}_{2} \mathrm{O}$ ) (100\%), 2,2'-dipicolylamine (1), (3-iodopropyl)trimethoxysilane (2) and $\mathrm{Zn}\left(\mathrm{NO}_{3}\right)_{2}$ were provided by Sigma-Aldrich and used as received. Sodium salts of fluoride, chloride, bromide, iodide, acetate, benzoate, sulfate, nitrate, phosphate, pyrophosphate, AMP, ADP, and ATP were purchased from Sigma-Aldrich. Analyticalgrade solvents were purchased from Scharlab (Barcelona, Spain). All reagents were used as received.

2.3. Synthesis of the mesoporous silica nanoparticles: $\mathrm{NaOH}\left(2.00 \mathrm{~mol} \mathrm{~L}{ }^{-1}, 3.5 \mathrm{~mL}\right)$ was added to a solution of CTAB $(1.00 \mathrm{~g}, 2.74 \mathrm{mmol})$ in deionized $\mathrm{H}_{2} \mathrm{O}(480 \mathrm{~mL})$. The solution temperature was adjusted to $80^{\circ} \mathrm{C}$ and then TEOS $\left(5.00 \mathrm{~mL}, 2.57 \times 10^{-2} \mathrm{~mol}\right)$ was added dropwise to the surfactant mixture. The mixture was stirred for $2 \mathrm{~h}$ to give a white precipitate. The solid was isolated by centrifugation and washed with deionized $\mathrm{H}_{2} \mathrm{O}$ and $\mathrm{EtOH}$ and then dried at $60^{\circ} \mathrm{C}$ for $12 \mathrm{~h}$ to give MCM-41. In order to remove the template phase, $\mathrm{MCM}-41$ was calcined at $550^{\circ} \mathrm{C}$ using an oxidizing atmosphere.

2.4. Synthesis of 3: 2,2'-dipicolylamine (1, $90.3 \mu \mathrm{L}, 0.5 \mathrm{mmol}$ ) and (3iodopropyl)trimethoxysilane $(2,98 \mu \mathrm{L}, 0.5 \mathrm{mmol})$ were dissolved in anhydrous toluene $(10 \mathrm{~mL})$ and degassed under an argon atmosphere. Then, triethylamine $(100 \mu \mathrm{L})$ was added to the mixture and the crude was refluxed for $16 \mathrm{~h}$. Afterward toluene was eliminated in a rotary evaporator and the orange sticky oil dissolved in chloroform (20 $\mathrm{mL})$ and washed with water $(2 \times 20 \mathrm{~mL})$. The organic layer was then dried with $\mathrm{Na}_{2} \mathrm{SO}_{4}$ and eliminated with a rotary evaporator. This afforded the final product $\mathbf{3}$ as orange oil (162.7 mg, $0.45 \mathrm{mmol}, 90 \%$ yield). ${ }^{1} \mathrm{H}$ NMR (400 MHz, $\mathrm{CD}_{2} \mathrm{Cl}_{2}$ ): $\delta=0.42$ (t, $2 \mathrm{H}$ ), 1.71 (m, 2H), 2.52 (t, 2H), 3.31 (s, 9H), $4.32(\mathrm{~s}, 4 \mathrm{H}), 7.12$ (t, 2H), 7.36 (d, 2H), $7.62(\mathrm{t}, 2 \mathrm{H})$, 8.42 (d, 2H); ${ }^{13} \mathrm{C}$ NMR (100 MHz, $\left.\mathrm{CD}_{2} \mathrm{Cl}_{2}\right): \delta=9.2$, 29.5, 47.1, 50, 124.2, 137.6, 148.2, 148.6, 154.1; HRMS-EI $\mathrm{m} / \mathrm{z}$ : calcd for $\mathrm{C}_{18} \mathrm{H}_{27} \mathrm{~N}_{3} \mathrm{O}_{3} \mathrm{Si}$ 361.1822; found: 361.1827.

2.5. Synthesis of Spyr: In a typical synthesis, template-free MCM-41 (1 g) and [Ru(bipy) $\left.{ }_{3}\right] \mathrm{Cl}_{2} \cdot 6 \mathrm{H}_{2} \mathrm{O}$ (570 mg, $0.76 \mathrm{mmol}$ ) were suspended in acetonitrile $(40 \mathrm{~mL})$ in a round-bottomed flask. To remove the adsorbed water, $10 \mathrm{~mL}$ of acetonitrile were distilled off using a Dean-Stark set-up. Then, the mixture was stirred for $24 \mathrm{~h}$ at room temperature for the purpose of achieving maximum loading in the pores of the MCM-41 scaffold. Afterwards an excess of compound 3 (450 mg, $1.25 \mathrm{mmol}$ ) was added to the reaction mixture, and the suspension was stirred for $5.5 \mathrm{~h}$. Finally, the orange-yellow solid (Spyr) was collected by filtration.

2.6. Synthesis of SZn: Solid Spyr ( $477 \mathrm{mg}$ ) was suspended in an acetonitrile solution (40 mL) that contains [Ru(bipy) $]_{3} \mathrm{Cl}_{2} \cdot 6 \mathrm{H}_{2} \mathrm{O}$ (286 mg, $0.38 \mathrm{mmol}$ ) in order to minimize the leaching of the $\left[\mathrm{Ru}(\text { bipy })_{3}\right]^{2+}$ dye from the pores of solid Spyr. Then, $\mathrm{Zn}\left(\mathrm{NO}_{3}\right)_{2}(580$ $\mathrm{mg}, 2.3 \mathrm{mmol}$ ) was added and the suspension stirred at reflux for $1 \mathrm{~h}$ in order to obtain the Zn(II)-dipicolylamine complex. Afterwards, the final solid SZn was collected by filtration and washed with acetonitrile.

\section{Results and discussion}

3.1. The gated material: The prepared hybrid solid is schematically shown in scheme 1. The MCM-41 mesoporous support was obtained, via well-known procedures, from tetraethyl orthosilicate (TEOS) as inorganic precursor and n-cetyltrimethylammonium bromide (CTAB) as a porogen species.[63] The surfactant was removed by calcination to obtain the final MCM-41 starting material. The solid was then loaded with $\left[\mathrm{Ru}(\mathrm{bipy})_{3}\right]^{2+}$, as suitable fluorophore, and the outer surface functionalized with the 
2,2'-dipicolylamine trialkoxysilane derivative 3 yielding solid Spyr. Following this grafting procedure, the silane groups are preferentially attached to the external surface rather than to the inside of the mesopores, which contain the $\left[\mathrm{Ru}(\mathrm{bipy})_{3}\right]^{2+}$ dye. In a second step, the $\mathrm{Zn}(\mathrm{II})-3$ complex was formed simple by adding $\mathrm{Zn}\left(\mathrm{NO}_{3}\right)_{2}$ to an acetonitrile suspension of solid Spyr which contain also the $\left[\mathrm{Ru}(\text { bipy) })_{3}\right]^{2+}$ dye (in order to minimize their leaching from the inner of the pores). This yielded the final material SZn that was moderately washed (in order to avoid the complete release of the entrapped dye) with acetonitrile before being dried overnight at $36^{\circ} \mathrm{C}$.

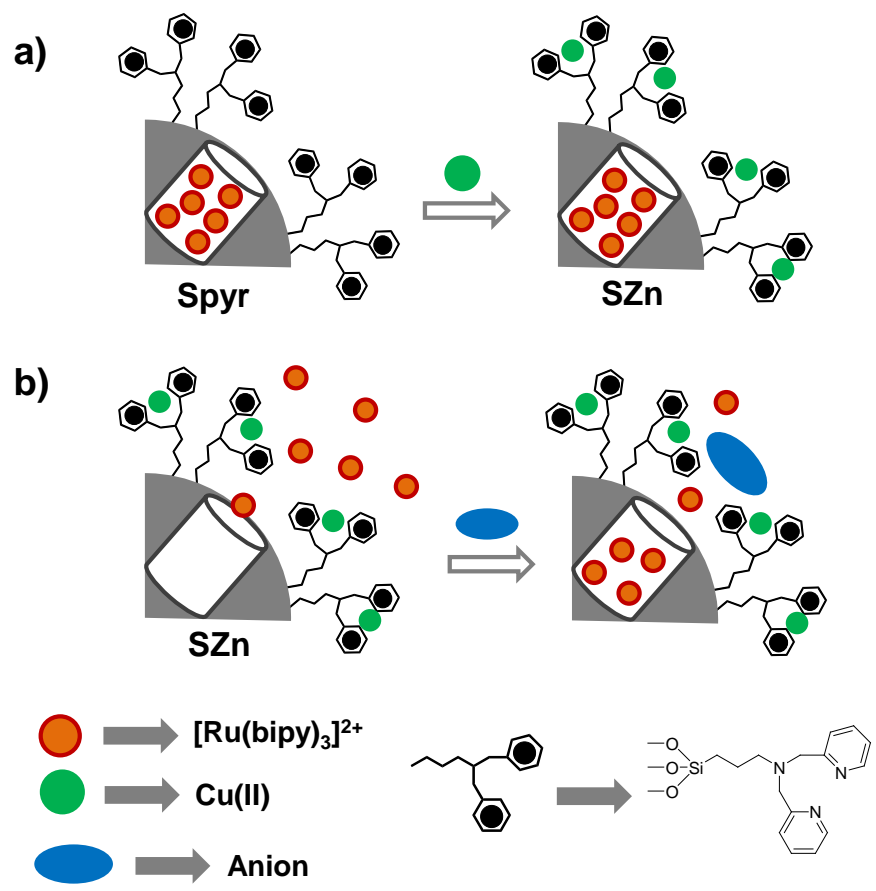

c)

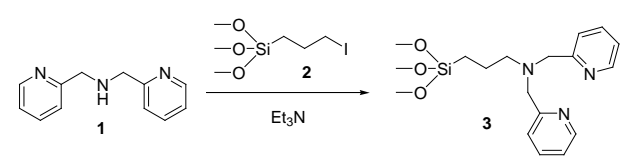

Scheme 1. Schematic representation of solids Spyr and SZn (a), mechanism of the anion tuned $\left[\mathrm{Ru}(\mathrm{bipy})_{3}\right]^{2+}$ dye release (b) and synthesis of 2,2'-dipicolylamine derivative 3 (c).

Compound 3, used in the preparation of the final material, was obtained in good yield through a nucleophilic substitution reaction between 2,2'-dipicolylamine (1) and (3-iodopropyl)trimethoxysilane (2) in the presence of triethylamine (see Scheme 1). The ${ }^{1} \mathrm{H}-\mathrm{NMR}$ spectra of $\mathbf{3}$ showed the typical signals of the monosubstituted pyridine heterocycles in the 7.0-8.5 interval whereas the propyl chain that linked the tertiary nitrogen and the silicon atoms appeared at 2.52, 1.71 and $0.42 \mathrm{ppm}$. Two singlets centered at 4.32 and $3.31 \mathrm{ppm}$ were ascribed to the methylene unit that linked the monosubstituted pyridines with the tertiary nitrogen atom and to the methoxysilyl subunits.

3.2. Materials characterization: The starting MCM-41 material and solid SZn were characterized by conventional solid state procedures. The mesoporous structure of the MCM-41 material was confirmed by powder X-ray diffraction (PXRD) and transmission electron microscopy (TEM) techniques. Figure 1 shows the PXRD pattern 
of the MCM-41 as-synthesized, MCM-41 calcined, and that of the final solid SZn. The PXRD of siliceous MCM-41 as-synthesized (curve a) shows four low-angle reflections typical of a hexagonal-ordered array which can be indexed as (100), (110), (200), and (210) Bragg peaks. A shift of the (100) reflection and a remarkable broadening of the (110) and (200) peaks in the PXRD of the MCM-41 calcined was observed (curve b). This corresponds to an approximate cell contraction of ca. 6-8 $\AA$ during the calcination step. Despite this partial order loss, the fact that the overlapped (100), (110) and (200) reflections were still observed indicates that the mesopore symmetry is preserved after calcination. The PXRD of the final solid (SZn, curve c) only displayed the (100) reflection. For this solid, peaks (110) and (200) were lost, most probably relating to a reduced contrast because of the pore voids filling with the ruthenium complex. Nevertheless, the clear presence of the (100) peak in this pattern indicate that the loading and functionalization process did not substantially modify the mesoporous structure of the final supports.

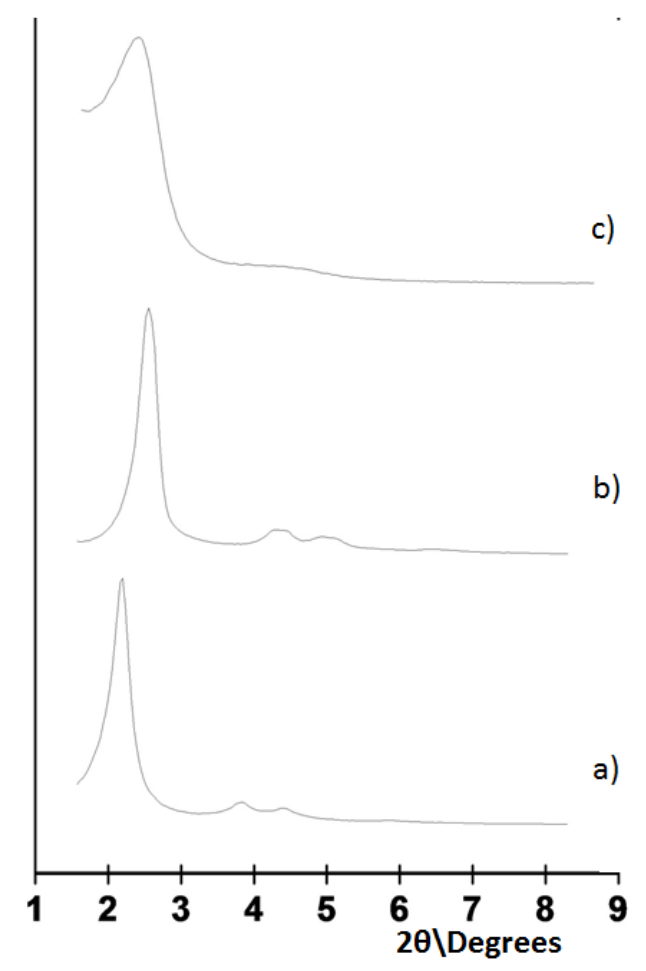

Figure 1. Small-angle PXRD patterns of as-synthesized MCM-41 (a), MCM-41 calcined (b), and the final solid SZn (c).
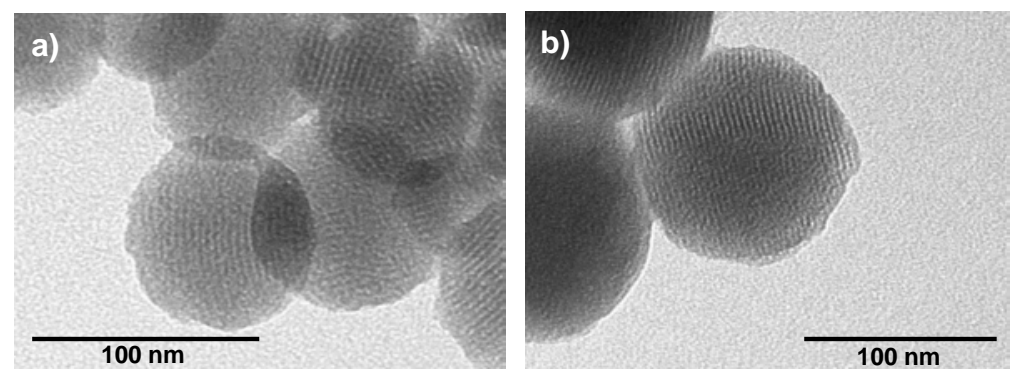

Figure 2. TEM images of a) MCM-41 calcined and b) the final solid SZn showing the typical porosity of the MCM-41 matrix. 
The presence of the mesoporous structure in the final functionalized solids was also confirmed by TEM analysis, in which the typical channels of the MCM-41 matrix are seen (Figure 2) as black and white stripes. TEM images also show that the final solid SZn was obtained as nanoparticles of ca. $100 \mathrm{~nm}$.

The $\mathrm{N}_{2}$ adsorption-desorption studies of the MCM-41 calcined and the final SZn materials were also carried out (see Figure 3). The MCM-41 calcined sample showed a typical curve for this mesoporous support, consisting of an adsorption step at an intermediate $P / P_{0}$ value (0.1-0.3). These isotherms could be classified as type IV, characteristic of mesoporous materials in which the observed step deals with nitrogen condensation inside the mesopores. Pore size distributions (PSD) of these samples, was calculated by employing the Barret-Joyner-Halenda (BJH) method.[64] The narrow $\mathrm{BJH}$ pore distribution and the absence of a hysteresis loop in this interval suggest the existence of uniform cylindrical mesopores (pore diameter of $2.76 \mathrm{~nm}$ and pore volume of $0.9 \mathrm{~cm}^{3} \mathrm{~g}^{-1}$ calculated by using the BJH model on the adsorption branch of the isotherm). Application of the Brunauer-Emmett-Teller (BET) model resulted in a value of $1045.7 \mathrm{~m}^{2} \mathrm{~g}^{-1}$ for the total specific surface (see Table 1).[65] From the PXRD, porosimetry, and TEM studies, an $a_{0}$ cell parameter value of $4.62 \mathrm{~nm}$ and a wall thickness of $1.86 \mathrm{~nm}$ were calculated.

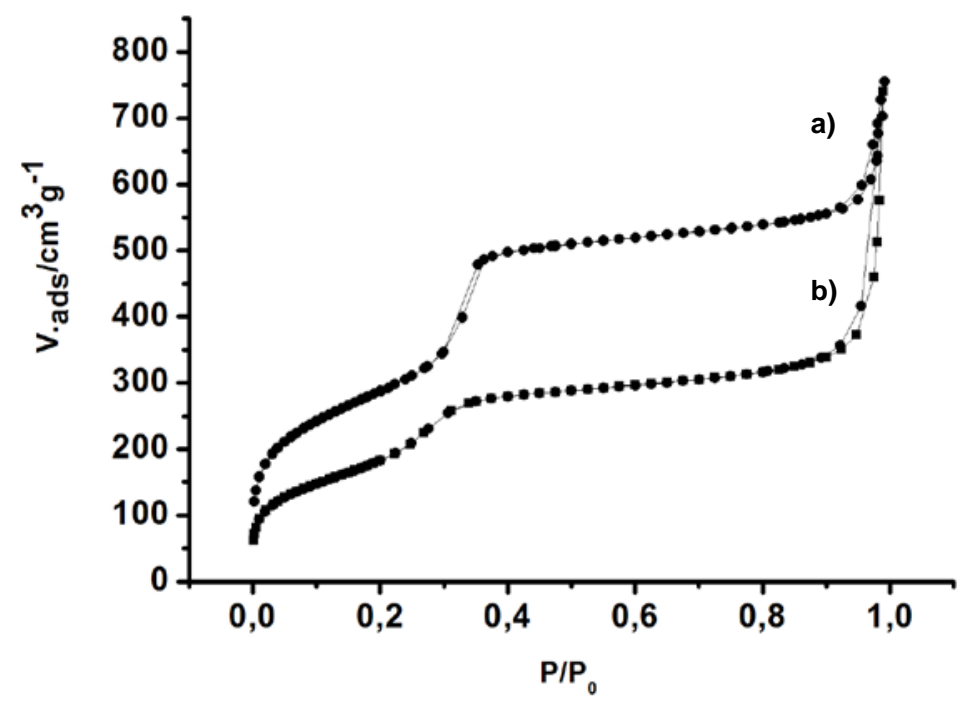

Figure 3. Nitrogen adsorption-desorption isotherms for MCM-41 calcined (a) and SZn solid (b).

Table 1. BET-specific surface values, pore volumes, and pore sizes calculated from the $\mathrm{N}_{2}$ adsorption-desorption isotherms.

\begin{tabular}{cccc}
\hline Sample & $\begin{array}{c}\mathrm{S}_{\mathrm{BET}} \\
{\left[\mathrm{m}^{2} \mathrm{~g}^{-1}\right]}\end{array}$ & $\begin{array}{c}\mathrm{BJH} \\
\text { Pore } \\
{[\mathrm{nm}]}\end{array}$ & $\begin{array}{c}\text { Total Pore } \\
\text { Volume } \\
{\left[\mathrm{cm}^{3} \mathrm{~g}^{-1}\right]}\end{array}$ \\
\hline MCM-41 & 1045.7 & 2.76 & 0.90 \\
SZn & 672.3 & 2.56 & 0.51 \\
\hline
\end{tabular}

[a] Pore volumes and pore sizes were associated with only intraparticle mesopores.

[b] Pore size estimated by the BJH model applied to the adsorption branch of the isotherm.

In contrast with the MCM-41 starting material the $\mathrm{N}_{2}$ adsorption-desorption isotherm of solid SZn is typical of a mesoporous system with partially filled mesopores and a decrease in the $\mathrm{N}_{2}$ volume adsorbed, specific surface area and specific volume is 
observed (see Table 1). This reduction in the BET surface, when compared with that of the MCM-41 support, is attributed to the loading of the pores with the ruthenium(II) dye and to the functionalization of the external surface with the Zn(II)-3 complex.

The content of the $\left[\mathrm{Ru}(\text { bipy })_{3}\right]^{2+}$ dye, 2,2'-dipicolylamine derivative $\mathbf{3}$ and Zn(II)-3 complex was determined by thermogravimetric and elemental analysis (see Table 2). Formation of Zn(II) 2,2'-dipicolylamine complex was also assessed by EDX measurements that confirmed the presence of zinc in final SZn solid.

Table 2. Content $(\alpha)$ of anchored molecules and dye in $\mathrm{mmol} \mathrm{g}^{-1}$ of $\mathrm{SiO}_{2}$.

\begin{tabular}{|c|c|c|c|}
\hline & $\alpha_{\mathrm{Ru}(\mathrm{II})}$ & $\alpha_{3}$ & $\alpha_{\mathrm{Zn}(\mathrm{II})-3}$ \\
\hline Solid & {$\left[\mathrm{mmol} \mathrm{g}^{-1} \mathrm{~s}\right.$} & {$\left[\mathrm{mmol} \mathrm{g}^{-1}\right.$} & {$\left[\mathrm{mmol} \mathrm{g}^{-1} \mathrm{SiO}_{2}\right]$} \\
\hline Spyr & 0.56 & 0.32 & - \\
\hline SZn & 0.54 & - & 0.30 \\
\hline
\end{tabular}

3.3. Dye release studies in the presence of anions: The release of the ruthenium(II) dye complex entrapped in the porous network of $\mathbf{S Z n}$ material was tested in water at $\mathrm{pH}$ 7.0 alone and in the presence of selected anions $\left(\mathrm{F}^{-}, \mathrm{Cl}^{-}, \mathrm{Br}^{-}, \mathrm{I}^{-}, \mathrm{AcO}^{-}, \mathrm{BzO}^{-}, \mathrm{SO}_{4}{ }^{2-}, \mathrm{NO}_{3}^{-}\right.$, $\mathrm{PO}_{4}{ }^{3-}, \mathrm{P}_{2} \mathrm{O}_{7}{ }^{2-}, \mathrm{ATP}, \mathrm{ADP}$ and AMP). In a typical assay, $1 \mathrm{mg}$ of solid $\mathbf{S Z n}$ was suspended in $3 \mathrm{~mL}$ of water at $\mathrm{pH} 7.0$ in the presence of the corresponding anion (at concentrations of $1.0 \times 10^{-2}$ or $1.0 \times 10^{-3} \mathrm{~mol} \mathrm{~L}^{-1}$, vide infra) at $25{ }^{\circ} \mathrm{C}$. Delivery of the dye to the bulk solution was easily detected by monitoring the $d-\pi$ metal-to-ligand charge transfer (MLCT) transition band of the [Ru(bipy) $\left.)_{3}\right]^{2+}$ complex at $453 \mathrm{~nm}$ in the solution.[66,67] The UV-visible spectra were measured after 60 minutes upon the addition of the corresponding anion in order to allow a complete dye delivery.

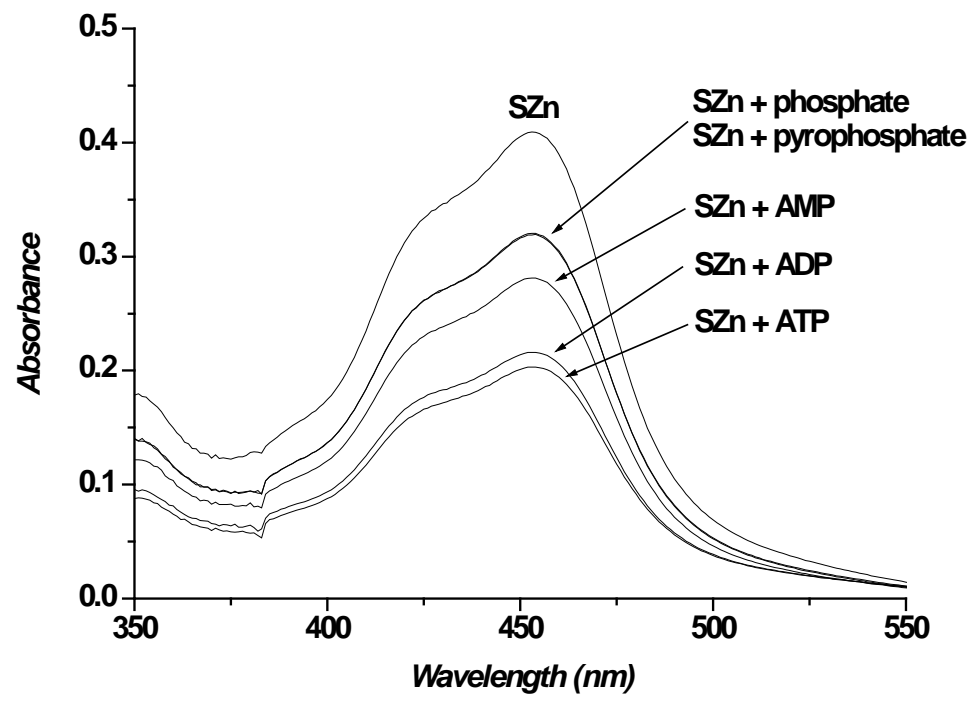

Figure 4. UV-visible of the $\left[\mathrm{Ru}(\text { bipy })_{3}\right]^{2+}$ complex released from solid SZn (1 mg in 3 $\mathrm{mL}$ of water at $\mathrm{pH} 7.0$ ) in the presence of selected anions at $1.0 \times 10^{-3} \mathrm{~mol} \mathrm{~L}^{-1}$ after 60 minutes.

Figure 4 shows the UV-visible spectra of the $\left[\mathrm{Ru}(\mathrm{bipy})_{3}\right]^{2+}$ complex released from solid SZn in the presence of selected anions at a concentration of $1.0 \times 10^{-3} \mathrm{~mol} \mathrm{~L}^{-}$ 
${ }^{1}$ after 60 minutes. No changes in dye delivery were observed in the presence of $\mathrm{F}^{-}, \mathrm{Cl}^{-}$, $\mathrm{Br}^{-}, \mathrm{I}^{-}, \mathrm{AcO}^{-}, \mathrm{BzO}^{-}, \mathrm{SO}_{4}{ }^{2-}$ and $\mathrm{NO}_{3}{ }^{-}$(data not shown) whereas in contrast the presence in the solution of phosphate, pyrophosphate, AMP, ADP or ATP induced some $\left[\mathrm{Ru}(\text { bipy })_{3}\right]^{2+}$ delivery inhibition. The interaction of these anions (i.e. ATP, ADP, AMP, pyrophosphate and phosphate) via electrostatic or coordinative forces with the Zn(II)-3 complex on the external surface of the mesoporous nanoparticles are most likely the cause of this behavior. In fact the interaction of $\mathrm{Zn}$ (II)-dipicolylamine complexes with both organic and inorganic phosphates is well documented and for instance has been extensively used for the preparation of selective fluorogenic probes for these anions.[6877] Moreover, in order to test the effect of the concentration of the anions on the $\left[\mathrm{Ru}(\text { bipy })_{3}\right]^{2+}$ dye release behavior of the $\mathbf{S Z n}$ material additional experiments were carried out using anions at a concentration of $1.0 \times 10^{-2} \mathrm{~mol} \mathrm{~L}^{-1}$. In this case nearly the same inhibition trend for solid SZn was observed (vide infra). However, the inhibition in dye release is in this case slightly higher due to the use of more concentrated anion solutions that results in a larger interaction with the positively charged $\mathrm{Zn}(\mathrm{II})-3$ complexes in SZn. In particular, the higher inhibition of $\left[\mathrm{Ru}(\text { bipy })_{3}\right]^{2+}$ delivery (61\%) was observed in the presence of ATP anion, whereas ADP, AMP, pyrophosphate and phosphate also induced remarkable pore blocking. The other anions tested induced small pore blocking indicating again a poor coordination with the anchored complex.
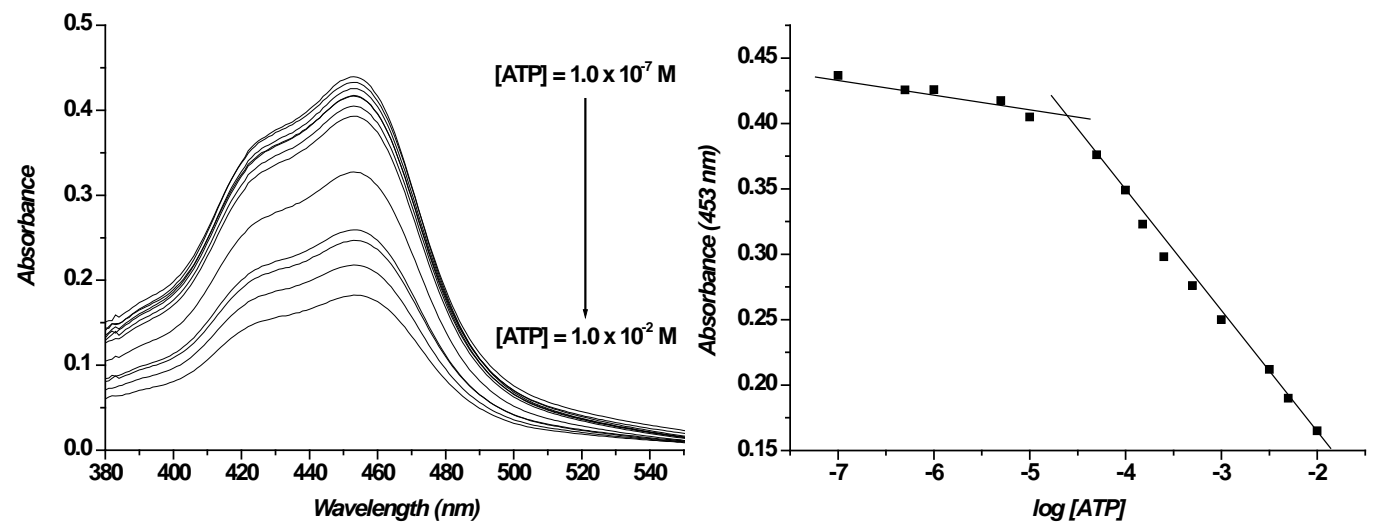

Figure 5. Left: UV-visible of the $\left[\mathrm{Ru}(\mathrm{bipy})_{3}\right]^{2+}$ complex released from solid $\mathbf{S Z n}$ in the presence of increasing quantities of ATP after 60 minutes. Right: Absorbance of the $\left[\mathrm{Ru}(\text { bipy })_{3}\right]^{2+}$ complex at $453 \mathrm{~nm}$ released from SZn solid upon addition of increasing quantities of ATP after 60 minutes.

In a further study ATP was selected for a more detailed dye delivery inhibition study. In a typical experiment, $\mathbf{S Z n}$ nanoparticles $(1 \mathrm{mg}$ ) were suspended in water at $\mathrm{pH}$ 7.0 (3 mL) and then, different quantities of ATP were added and the delivery of the dye to the bulk solution was again easily detected via monitoring the $\left[\mathrm{Ru}(\mathrm{bipy})_{3}\right]^{2+}$ absorbance at $453 \mathrm{~nm}$. As an example, the curve obtained in the presence of increasing amounts of ATP to SZn suspensions is depicted in Figure 5. As it can be seen, the absorbance at $453 \mathrm{~nm}$ decreased upon the increase of the ATP concentration. From the calibration curve of ATP (see Figure 5) it can be established that concentration larger than $25 \mu \mathrm{M}$ for this anion are able to start to induce an important cargo release inhibition.

A closely view to the modulation of the $\left[\mathrm{Ru}(\mathrm{bipy})_{3}\right]^{2+}$ release from solid $\mathbf{S Z n}$ in the presence of selected anions showed certain general trends. In particular it is apparent 
from the observed results that dye delivery is a combination of several effects; the coordination affinity of a certain anion for the $\mathrm{Zn}(\mathrm{II})-3$ complexes, the size and charge of the anions and the possibility to form hydrogen bonding interactions. The first effect can be seen for instance when the delivery behavior in the presence of sulfate and phosphate is compared. Thus, although both anions have a similar size only phosphate is able to induce some cargo delivery from SZn. This is not a consequence of the charge of the anion (sulfate exists at neutral $\mathrm{pH}$ as a dianion $\mathrm{SO}_{4}{ }^{2-}$, whereas phosphate is as a mixture of $\mathrm{H}_{2} \mathrm{PO}_{4}{ }^{-}$and $\mathrm{HPO}_{4}{ }^{2-}$ species), but is tentatively related with the different coordinating ability of the anion with the Zn(II)-3 core. In fact phosphate has been reported to display a high affinity for $\mathrm{Zn}(\mathrm{II})$-3-like complexes.[68-77] Moreover the effect of the anion size (and charge, vide infra) can be observed when the anion series phosphate, pyrophosphate, AMP, ADP or ATP is compared. In this case all these anions have been reported to form complexes with $\mathrm{Zn}$ (II)-3-like complexes and the different cargo release is related with their different size; i.e. larger anions trend to induce a larger delivery inhibition at a certain concentration. This relationship between the size of the anions and the observed dye release is clearly observed in Figure 6 that shows the absorbance at $453 \mathrm{~nm}$ of the $\left[\mathrm{Ru}(\mathrm{bipy})_{3}\right]^{2+}$ complex in the presence of selected anions (at $1.0 \times 10^{-2} \mathrm{~mol} \mathrm{~L}^{-1}$ ) after 60 minutes vs. their diameter (considering the anions as smooth spheres).[78] A nearly linear relationship between the absorbance at $453 \mathrm{~nm}$ (directly related with the amount of $\left[\mathrm{Ru}(\mathrm{bipy})_{3}\right]^{2+}$ released) and the anion diameter is observed.

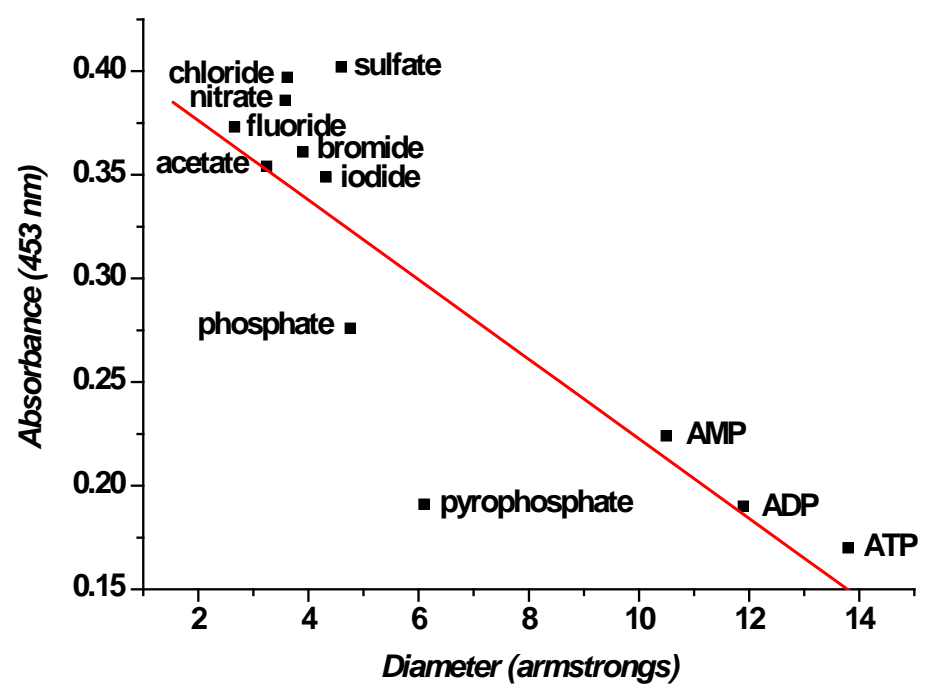

Figure 6. Absorbance of $\left[\mathrm{Ru}(\mathrm{bipy})_{3}\right]^{2+}$ complex released from solid SZn (measured at $453 \mathrm{~nm})$ upon addition of the correspondent anion $\left(1.0 \times 10^{-2} \mathrm{~mol} \mathrm{~L}^{-1}\right)$ vs. diameter of the anion.[78]

The charge of the anion is also an important factor that modulated the release of $\left[\mathrm{Ru}(\text { bipy })_{3}\right]^{2+}$ complex. At $\mathrm{pH} 7.0$ phosphate anion is in the $\mathrm{H}_{2} \mathrm{PO}_{4}{ }^{-}$and $\mathrm{HPO}_{4}{ }^{2-}$ forms (with an average charge of -1.38) whereas pyrophosphate is a mixture of $\mathrm{H}_{2} \mathrm{P}_{2} \mathrm{O}_{7}{ }^{2-}$ and $\mathrm{HP}_{2} \mathrm{O}_{7}{ }^{3-}$ (with an average charge of -2.72). In the case of nucleotides, at $\mathrm{pH} 7.0$ there are mixtures of $\mathrm{ATP}^{4-} / \mathrm{ATP}^{3-}, \mathrm{ADP}^{3-} / \mathrm{ADP}^{2-}$ and $\mathrm{AMP}^{2-} / \mathrm{AMP}^{-}$forms. Figure 7 shows the $\left[\mathrm{Ru}(\text { bipy) })_{3}\right]^{2+}$ complex released (from the absorbance measured at $453 \mathrm{~nm}$ ) vs. the average charge of the inorganic and organic phosphates tested at a concentration of 1.0 $\mathrm{x} 10^{-2} \mathrm{~mol} \mathrm{~L}{ }^{-1}$. As seen there is a clear linear relationship between the average charge of 
the anion and the absorbance of the $\left[\mathrm{Ru}(\mathrm{bipy})_{3}\right]^{2+}$ complex released from solid SZn. The more the negative charge the higher the inhibition degree. In particular, ATP (with an average charge of -3.7 at $\mathrm{pH}$ 7.0) induced the higher pore blockage whereas pyrophosphate and ADP (with a similar average charge) are able to release similar quantities of $\left[\mathrm{Ru}(\mathrm{bipy})_{3}\right]^{2+}$ complex. On the other hand, AMP and phosphate presented the lower average charges and, as a clear consequence, induced smaller pore blockage.

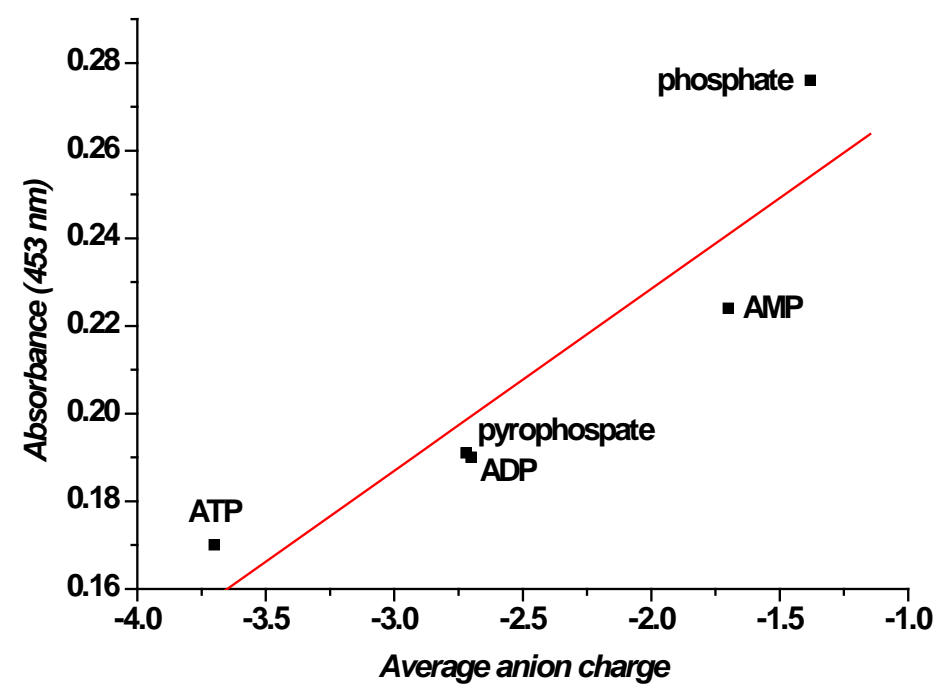

Figure 7. Absorbance of $\left[\mathrm{Ru}(\mathrm{bipy})_{3}\right]^{2+}$ complex released from solid SZn (measured at $453 \mathrm{~nm})$ upon addition of the correspondent anion $\left(1.0 \times 10^{-2} \mathrm{~mol} \mathrm{~L}^{-1}\right)$ vs. average anion charge.

In addition, the different inhibition degree for phosphate and pyrophosphate observed in Figure 7 could be also related, not only to their difference in charge and size, but also to the difference in the possibility of building a hydrogen-bond network around the pore outlets. At this respect, at $\mathrm{pH} 7.0$ pyrophosphate has more reactive points able to give hydrogen bonds than phosphate. The formation of a dense monolayer of pyrophosphate anions, coordinated with the $\mathrm{Zn}$ (II)-3 core and interconnected through additional hydrogen bonds could induce a severe pore blockage with the subsequent inhibition of $\left[\mathrm{Ru}(\mathrm{bipy})_{3}\right]^{2+}$ complex release.

\section{Conclusions}

The study of new protocols for controlling cargo release from mesoporous materials is a captivating area for scientists due to its possible impact in the development of new technologies for delivery applications. In particular we have reported herein the preparation and characterization of a new organic-inorganic gated hybrid material SZn. This material consists of a mesoporous MCM-41-like structure loaded with the $\left[\mathrm{Ru}(\text { bipy })_{3}\right]^{2+}$ dye and functionalized, in the external surface, with $\mathrm{Zn}$ (II)-dipicolylamine complexes. Solid SZn is able to release the entrapped $\left[\mathrm{Ru}(\mathrm{bipy})_{3}\right]^{2+}$ dye when suspended in water solution at $\mathrm{pH} 7.0$ because the $\mathrm{Zn}$ (II)-dipicolylamine complexes are too small to induce pore blockage. The dye release could be modulated by the addition of anions with different sizes. In particular organic (such as ATP, ADP and AMP) and inorganic (phosphate and pyrophosphate) phosphates are able to induce a inhibition of $\left[\mathrm{Ru}(\mathrm{bipy})_{3}\right]^{2+}$ dye release due to the formation of complexes between these anions and the grafted Zn(II)-dipicolylamine moieties. Maximum delivery inhibition was observed 
for the bulky and highly charged ATP anion. The obtained results suggest that SZn or very similar gated solids (functionalized on the external surfaces with different metal complexes) could be used for the preparation of new materials able to control cargo delivery via their interaction with selector anions in the solution.

\section{Acknowledgements}

Financial support from the Spanish Government (project MAT2012-38429-C04-01) and the Generalitat Valencia (project PROMETEO/2009/016) is gratefully acknowledged.

\section{References}

[1] M. Hamidi, A. Azadi, P. Rafiei, Adv. Drug Delivery Rev. 60 (2008) 1638.

[2] C. W. Pouton, C. J. H. Porter, Adv. Drug Delivery Rev. 60 (2008) 625.

[3] C. J. F. Rijcken, O. Soga, W. E. Hennink, C. F. van Nostrum, J. Controlled Release 120 (2007) 131.

[4] U. Boas, P. M. H. Heegaard, Chem. Soc. Rev. 33 (2004) 43.

[5] K. E. Uhrich, S. M. Cannizzaro, R. S. Langer, K. M. Shakesheff, Chem. Rev. 99 (1999) 3181.

[6] E. Aznar, R. Martínez-Máñez, F. Sancenón, Expert Opin. Drug Deliver. 6 (2009) 643.

[7] C. T. Kresge, M. E. Leonowicz, W. J. Roth, J. C. Vartuli, J. S. Beck, Nature 359 (1992) 710.

[8] D. Zhao, J. Feng, Q. Huo, N. Melosh, G. H. Fredrickson, B. F. Chmelka, G. D. Stucky, Science 279 (1998) 548.

[9] J. S. Beck, J. C. Vartuli, W. J. Roth, M. E. Leonowicz, C. T. Kresge, K. D.Schmitt, C. T. -W. Chu, D. H. Olson, E. W. Sheppard, B. S. McCullen, J. B. Higgins, J. L. Schlenker, J. Am. Chem. Soc. 114 (1992) 10834.

[10] A. P. Wright, M. E. Davis, Chem. Rev. 102 (2002) 3589.

[11] G. Kickelbick, Angew. Chem. Int. Ed. 43 (2004) 3102.

[12] M. Vallet-Regí, A. Rámila, R. P. del Real, J. Pérez-Pariente, J. Mater. Chem. 13 (2001) 308.

[13] M. Vallet-Regí, F. Balas, D. Arcos, Angew. Chem. Int. Ed. 46 (2007) 7548.

[14] B. G. Trewyn, I. I. Slowing, S.Giri, H. -T. Chen, V. S. -Y. Lin, Acc. Chem. Res. 40 (2007) 846.

[15] I. I. Slowing, J. L. Vivero-Escoto, C. W. Wu, V. S. -Y. Lin, Adv. Drug Delivery Rev. 60 (2008) 1278.

[16] K. Cotí, M. E. Belowich, M. Liong, M. W. Ambrogio, Y. A. Lau, H. A. Khatib, J. I. Zink, N. M. Khashab, J. F. Stoddart, Nanoscale 1 (2009) 16.

[17] N. K. Mal, M. Fujiwara, Y. Tanaka, Nature 421 (2003) 350.

[18] T. M, Guardado-Alvarez, L. S. Devi, M. M. Russell, B. J. Schwartz, J. I. Zink, J. Am. Chem. Soc. 135 (2013) 14000.

[19] R. Liu, Y. Zhang, P. Feng, J. Am. Chem. Soc. 131 (2009) 15128.

[20] C. Park, K. Lee, C. Kim, Angew. Chem. Int. Ed. 48 (2009) 1275.

[21] R. Hernandez, H. -R. Tseng, J. W. Wong, J. F. Stoddart, J. I. Zink, J. Am. Chem. Soc. 126 (2004) 3370.

[22] R. Liu, X. Zhao, T. Wu, P. Feng, J. Am. Chem. Soc. 130 (2008) 14418.

[23] A. M. Sauer, A. Schlossbauer, N. Ruthardt, V. Cauda, T. Bein, C. Bräuchle, Nanoletters 10 (2010) 3684.

[24] C. Park, K. Oh, S. C. Lee, C. Kim, Angew. Chem. Int. Ed. 46 (2007) 1455. 
[25] S. Angelos, N. M. Khashab, Y. -W. Yang, A. Trabolsi, H. A. Khatib, J. F. Stoddart, J. I. Zink, J. Am. Chem. Soc. 131 (2009) 12912.

[26] R. Liu, Y. Zhang, X. Zhao, A. Agarwal, L. J. Mueller, P. Feng, J. Am. Chem. Soc. 132 (2010) 1500.

[27] C. Coll, R. Casasús, E. Aznar, M. D. Marcos, R. Martínez-Máñez, F. Sancenón, J. Soto, P. Amorós, Chem. Commun. (2007) 1957.

[28] C. Chen, J. Geng, F. Pu, X. Yang, J. Ren, X. Qu, Angew. Chem. Int. Ed. 50 (2011) 882.

[29] Y.-Z. You, K. K. Kalebaila, S. L. Brock, D. Oupický, Chem. Mater. 20 (2008) 3354.

[30] E. Aznar, L. Mondragón, J. V. Ros-Lis, F. Sancenón, M. D. Marcos, R, MartínezMáñez, J. Soto, E. Pérez-Payá, P. Amorós, Angew. Chem. Int. Ed. 50 (2011) 11172.

[31] a) A. Bernardos, E. Aznar, M. D. Marcos, R. Martínez-Máñez, F. Sancenón, J. Soto, J. M. Barat, P. Amorós, Angew. Chem. Int. Ed. 48 (2009) 5884; b) A. Agostini, L. Mondragón, C. Coll, E. Aznar, M.D. Marcos, R. Martínez-Máñez, F. Sancenón, J. Soto, E. Pérez-Payá, P. Amorós, ChemistryOpen 1 (2012) 17.

[32] K. Patel, S. Angelos, W. R. Dichtel, A. Coskun, Y. -W. Yang, J. I. Zink, J. F. Stoddart, J. Am. Chem. Soc. 130 (2008) 2382.

[33] A. Schlossbauer, J. Kecht, T. Bein, Angew. Chem. Int. Ed. 48 (2009) 3092.

[34] C. Coll, A. Bernardos, R. Martínez-Máñez, F. Sancenón, Acc. Chem. Res. 46 (2013) 339.

[35] A. B. Descalzo, R. Martínez-Máñez, F. Sancenón, K. Hoffmann, K. Rurack, Angew. Chem. Int. Ed. 45 (2006) 5924.

[36] N. L. Rosi, C. A. Mirkin, Chem. Rev. 105 (2005) 1547.

[37] E. Katz, I. Willner, Angew. Chem. Int. Ed. 43 (2004) 6042.

[38] R. Casasús, E. Aznar, M. D. Marcos, R. Martínez-Máñez, F. Sancenón, J. Soto, P. Amorós, Angew. Chem. Int. Ed. 45 (2006) 6661.

[39] V. C. Özalp, T. Schäfer, Chem. Eur. J. 17 (2011) 9893.

[40] C. -L. Zhu, C. -H. Lu, X. -Y. Song, H. -H. Yang, X. -R. Wang, J. Am. Chem. Soc. 133 (2011) 1278.

[41] X. He, Y. Zhao, D. He, K. Wang, F. Xu, J. Tang, Langmuir 28 (2012) 12909.

[42] E. Climent, M. D. Marcos, R. Martínez-Máñez, F. Sancenón, J. Soto, K. Rurack, P. Amoros, Angew. Chem. Int. Ed. 48 (2009) 8519.

[43] E. Aznar, C. Coll, M. D. Marcos, R. Martínez-Máñez, F. Sancenón, J. Soto, P. Amorós, J. Cano, E. Ruiz, Chem. Eur. J. 15 (2009) 6877.

[44] E. Climent, A. Bernardos, R. Martínez-Máñez, A. Maquieira, M. D. Marcos, N. Pastor-Navarro, R. Puchades, F. Sancenón, J. Soto, P. Amorós, J. Am. Chem. Soc. 131 (2009) 14075.

[45] E. Climent, R. Martínez-Máñez, F. Sancenón, M. D. Marcos, J. Soto, A. Maquieira, P. Amorós, Angew. Chem. Int. Ed. 49 (2010) 7281.

[46] C. Coll, E. Aznar, R. Martínez-Máñez, M. D. Marcos, F. Sancenón, J. Soto, P. Amorós, J. Cano, E. Ruiz, Chem. Eur. J. 16 (2010) 10048.

[47] I. Candel, A. Bernardos, E. Climent, M. D. Marcos, R. Martínez-Máñez, F. Sancenón, J. Soto, A. M. Costero, S. Gil, M. Parra, Chem. Commun. 47 (2011) 8313.

[48] E. Climent, R. Martínez-Máñez, A. Maquiera, F. Sancenón, M. D. Marcos, E. M. Brun, J. Soto, P. Amorós, ChemistryOpen 1 (2012) 251.

[49] Y. Salinas, A. Agostini, E. Pérez-Esteve, R. Martínez-Máñez, F. Sancenón, M. D. Marcos, J. Soto, A. M. Costero, S. Gil, M. Parra, P. Amorós, J. Mater. Chem. A 1 (2013) 3561. 
[50] Y. Salinas, R. Martínez-Máñez, J. O. Jeppesen, L. H. Petersen, F. Sancenón, M. D. Marcos, J. Soto, C. Guillem, P. Amorós, ACS Appl. Mater. Interfaces 5 (2013) 1538.

[51] E. Climent, L. Mondragón, R. Martínez-Máñez, F. Sancenón, M. D. Marcos, J. R. Murguía, P. Amorós, K. Rurack, E. Pérez-Payá, Angew. Chem. Int. Ed. 52 (2013) 8938. [52] M. Oroval, E. Climent, C. Coll, R. Eritja, A. Aviñó, M. D. Marcos, F. Sancenón, R. Martínez-Máñez, P. Amoros, Chem. Commun. 49 (2013) 5480.

[53] E. Climent, D. Gröninger, M. Hecht, M. A. Walter, R. Martínez-Máñez, M. G. Weller, F. Sancenón, P. Amorós, K. Rurack, Chem. Eur. J. 19 (2013) 4117.

[54] E. Aznar, R. Villalonga, C. Giménez, F. Sancenón, M. D. Marcos, R. MartínezMáñez, P. Díez, J. M. Pingarrón, P. Amorós, Chem. Commun. 49 (2013) 6391.

[55] Y. Zhao, B. G. Trewyn, I. I. Slowing, V. S. -Y. Lin, J. Am. Chem. Soc. 131 (2009) 8398.

[56] S. Wu, X. Huang, X. Du, Angew. Chem. Int. Ed. 52 (2013) 5580.

[57] M. Chen, C. Huang, C. He, W. Zhu, Y. Xu, Y. Lu, Chem. Commun. 48 (2012) 9522.

[58] L. Chen, Y. Wen, B. Su, J. Di, Y. Song, L. Jiang, J. Mater. Chem. 21 (2011) 13811.

[59] Y. L. Choi, J. Jaworski, M. L. Seo, S. J. Lee, J. H. Jung, J. Mater. Chem. 21 (2011) 7882.

[60] Y. Zhang, Q. Yuan, T. Chen, X. Zhang, Y. Chen, W. Tan, Anal. Chem. 84 (2012) 1956.

[61] Z. Zhang, D. Balogh, F. Wang, I. Willner, J. Am. Chem. Soc. 135 (2013) 1934.

[62] E. Aznar, F. Sancenón, M. D. Marcos, R. Martínez-Máñez, P. Stroeve, J. Cano, P. Amorós, Langmuir 28 (2012) 2986.

[63] S. Cabrera, J. El Haskouri, C. Guillem, J. Latorre, A. Beltrán, D. Beltrán, M. D. Marcos, P. Amorós, Solid State Sci. 2 (2000) 405.

[64] E. P. Barret, L. G. Joyner, P. P. Halenda, J. Am. Chem. Soc. 73 (1951) 373.

[65] S. Brunauer, P. H. Emmet, E. Teller, J. Am. Chem. Soc. 60 (1938) 309.

[66] F. Felix, J. Ferguson, H. U. Gudel, A. Ludi, J. Am. Chem. Soc. 102 (1980) 4096.

[67] F. E. Lytle, D. M. Hercules, J. Am. Chem. Soc. 91 (1969) 253.

[68] A. Ojida, S. -K. Park, M. Yasuko, I. Hamachi, Tetrahedron Lett. 43 (2002) 6193.

[69] A. Ojida, Y. Mito-oka, K. Sada, I. Hamachi, J. Am. Chem. Soc., 126 (2004) 2454.

[70] X. Chen, M. J. Jou, J. Yoon, Org. Lett. 11 (2009) 2181.

[71] Y. Kurishita, T. Kohira, A. Ojida, I. Hamachi, J. Am. Chem. Soc. 132 (2010) 13290.

[72] H. J. Kim, J. H. Lee, J. -I. Hong, Tetrahedron Lett. 52 (2011) 4944.

[73] M. J. Kim, K. M. K. Swamy, K. M. Lee, A. R. Jagdale, Y. Kim, S. -J. Kim, K. H. Yoo, J. Yoon, Chem. Commun. (2009) 7215.

[74] Z. Xu, D. R. Spring, J. Yoon, Chem. As. J. 6 (2011) 2114.

[75] C. Park, J. -I. Hong, Tetrahedron Lett. 51 (2010) 1960.

[76] A. J. Moro, P. J. Cywinsky, S. Körsten, G. J. Möhr, Chem. Commun. 46 (2010) 1085.

[77] W. -H. Chen, Y. Xing, Y. Pang, Org. Lett. 13 (2011) 1362.

[78] Y. Marcus, H. D. Brooke-Jenkins, L. Glasser, J. Chem. Soc., Dalton Trans. (2002) 3795. 